\title{
ANALISIS PENDAPATAN DAN FAKTOR-FAKTOR YANG MEMPENGARUHI PENDAPATAN NELAYAN TRADISIONAL DI DESA LAMBADA LHOK KECAMATAN BAITUSSALAM KABUPATEN ACEH BESAR
}

\author{
(Analysis of Income and The Factors That Affect The Income Of Traditional \\ Fishermen In The Village Lambada Lhok The District Baitussalam Of \\ Aceh Besar)
}

\author{
Ivo Yolanda ${ }^{1}$, Suyanti Kasimin ${ }^{1}$, Mustafa Usman ${ }^{1 *}$ \\ ${ }^{1}$ Program Studi Agribisnis, Fakultas Pertanian, Universitas Syiah Kuala
}

\begin{abstract}
Abstrak -Nelayan tradisional adalah orang yang mata pencahariannya melakukan penangkapan ikan di laut untuk memenuhi kebutuhan hidup sehari-hari dengan menggunakan kapal berukuran paling besar 5 GT (Gross Ton). Nelayan tradisional tidak semuanya memiliki alat tangkap, nelayan yang demikian harus bekerja pada orang lain yang membutuhkan tenaganya. Sistem bagi hasil yang dilakukan para pemilik kapal cenderung kurang menguntungkan nelayan tradisional yang berada di Desa Lambada Lhok Kecamatan Baitussalam Kabupaten Aceh Besar. Faktor-faktor yang mempengaruhi pendapatan nelayan tradisional yaitu pengalaman, umur, pendidikan, jumlah tanggungan dan biaya operasional. Penelitian ini bertujuan untuk mengetahui usaha nelayan tradisional dapat memberikan pendapatan yang layak atau tidak bagi nelayan tradisional dan mengetahui faktorfaktor tingkat pendapatan nelayan tradisional. Metode analisis yang digunakan adalah analisis pendapatan dan analisis regresi linear berganda. Hasil penelitian menunjukkan bahwa pendapatan nelayan tradisional sebesar Rp. 1.335.905/bulan. Hasil R/C sebesar 1,67 menunjukkan bahwa pendapatan nelayan tradisonal menguntungkan. Faktor-faktor yang mempengaruhi pendapatan yaitu jumlah tanggungan, umur, pendidikan, pengalaman dan biaya operasional berpengaruh signifikan terhadap pendapatan nelayan tradisional.
\end{abstract}

Kata Kunci: Nelayan Tradisional, Sistem Bagi Hasil, Faktor-Faktor yang Mempengaruhi Pendapatan Nelayan

\begin{abstract}
Small fishermen are people whose livelihood is fishing in the sea to meet the needs of everyday life by using large-sized ships least 5 GT (Gross Tonnes). Fishermen traditional not all have fishing gear, fishermen should work with others people who need strength. Profit-sharing system made by ship owners tend to be less profitable traditional fishermen in the village of Lambada Lhok, Aceh Besar District Subdistrict Baitussalam. Factors that affect the income of the traditional fishermen are experience, age, education, number of dependents and operational costs. The study aims to know the bussiness of traditional fishermen can provide decent income or not for traditional fishermen and factors of income level the traditional fishermen. The method of analysis used is the analysis of income and the analysis of the regression of the linear risks. The results showed that the income of the traditional fishermen Rp. 1,335,905 / month. The results of the R / C of 1.67 indicates that the income of traditional fishermen profitable. Factors that affect the income of which is the number of dependents, age, education, experience and operational costs significantly influence the traditional fishermen income.
\end{abstract}

Keywords: Traditional Fishermen, Profit Sharing, factors of fishermen income

\section{PENDAHULUAN}

Nelayan tradisional adalah orang yang pekerjaannya melakukan penangkapan ikan dengan menggunakan perahu dan alat tangkap yang sederhana. Dengan keterbatasan perahu maupun alat tangkapnya, maka jangkauan wilayah penangkapannya menjadi terbatas biasanya hanya berjarak 6 mil laut dari garis pantai. Nelayan tradisonal ini biasanya adalah nelayan yang turun-temurun yang melakukan penangkapan ikan untuk mencukupi kebutuhan hidupnya (Retnowati, 2011).

*Corresponding author: musthafa.koti@gmail.com 
Indonesia merupakan negara maritim yang memiliki luas perairan mencapai 3,25 juta $\mathrm{km}^{2}$ atau sekitar $63 \%$ wilayah Indonesia dan memiliki garis pantai sepanjang $95.181 \mathrm{~km}$. Luas perairan tersebut, termasuk didalamnya laut, memiliki potensi produksi lestari ikan laut yang cukup besar, dengan asumsi sekitar 6,51 juta ton/tahun atau 8,2\% dari total potensi produksi ikan laut dunia.

Indonesia merupakan negara yang kaya akan hasil sumber daya alam, salah satunya hasil laut. Menurut BPS pada tahun 2014, jumlah produksi ikan tangkap sebesar 5.707.012 ton dan jumlah nelayan sebanyak 671.625 orang. Dengan jumlah produksi ikan tersebut, nelayan tetap memperoleh pendapatan yang rendah. Rata-rata pendapatan nelayan tradisional dari hasil melaut sebesar Rp. 1.831.818/bulan (Pratama, 2012).

Secara umum, nelayan tradisional lebih berorientasi pada pemenuhan kebutuhan sendiri. Dalam arti hasil tangkapan yang dijual lebih banyak dipergunakan untuk memenuhi kebutuhan pokok sehari-hari khususnya pangan, dan tidak diinvestasikan kembali untuk pengembangan skala usaha. Berbeda dengan nelayan modern yang seringkali mampu merespon perubahan dan lebih mampu dalam menyiasati tekanan perubahan dan kondisi over fishing, nelayan tradisional justru seringkali mengalami proses marginalisasi dan menjadi korban dari program pembangunan dan modernisasi perikanan yang sifatnya berubah-ubah. Akibat keterbatasan teknologi yang dimiliki, ruang-gerak nelayan tradisional umumnya sangat terbatas, mereka hanya mampu beroperasi di perairan pantai. Kegiatan penangkapan ikan dilakukan dalam satu hari sekali melaut (one day a fishing trip) (Kusnadi, 2003).

Nelayan tradisional masih mengalami keterbatasan teknologi penangkapan. Selain itu, tidak semua nelayan memiliki alat tangkap. Bagi nelayan yang demikian tidak ada alternatif lain kecuali harus bekerja pada orang lain yang membutuhkan tenaganya. Permasalahannya adalah selain minimnya hasil tangkapan dengan alat tangkap sederhana, sistem bagi hasil yang dilakukan para pemilik kapal cenderung kurang menguntungkan nelayan tradisional. Hal ini terjadi karena penghasilan nelayan yang tidak dapat ditentukan kepastiannya tergantung dari jumlah ikan yang ditangkap dan hasil penjualan yang dilakukan (Mulyadi, 2005).

Desa Lambada Lhok Kecamatan Baitussalam Kabupaten Aceh Besar merupakan desa yang berada di wilayah pesisir. Sebagian besar penduduk desa Lambada Lhok bermata pencaharian sebagai nelayan tradisional. Permasalahan yang dihadapi oleh masyarakat nelayan dari dulu sampai saat ini adalah kehidupan nelayan yang tidak dapat memenuhi kebutuhan hidup.

Tingkat kesejahteraan nelayan sangat dipengaruhi oleh hasil tangkapannya. Jika hasil tangkapannya tinggi, maka pendapatan mereka juga baik dan begitu pula sebaliknya. Selain itu, beberapa faktor yang mempengaruhi pendapatan nelayan menurut Sujarno (2008) yang terdiri dari pengalaman, umur, pendidikan, jumlah tanggungan dan biaya operasional. Adapun tujuan dari penelitian ini adalah: (1) Untuk mengetahui apakah usaha nelayan dapat memberikan pendapatan yang layak bagi nelayan tradisional dari melaut di Desa Lambada Lhok Kecamatan Baitussalam, dan (2) Untuk mengetahui faktor-faktor yang mempengaruhi tingkat pendapatan nelayan tradisional di Desa Lambada Lhok Kecamatan Baitussalam.

\section{METODE PENELITIAN}

Penelitian ini dilakukan di Kecamatan Baitussalam, Kabupaten Aceh Besar. Lokasi penelitian ini difokuskan pada Desa Lambada Lhok karena masyarakat di desa tersebut hampir seluruhnya bermata pencarian nelayan tradisional. Objek dari penelitian ini adalah

Analisis Pendapatan dan Faktor-Faktor yang Mempengaruhi Pendapatan Nelayan Tradisional DI Desa Lambada 
nelayan tradisional. Ruang lingkup penelitian ini terbatas pada analisis pendapatan dan faktorfaktor yang mempengaruhi pendapatan nelayan tradisional.

\section{Metode Penelitian dan Jenis Data}

Metode yang digunakan pada penelitian ini adalah metode survei. Metode survei adalah penyelidikan yang dilakukan untuk memperoleh fakta-fakta dari gejala-gejala yang ada dan mencari keterangan secara faktual, baik tentang institusi sosial, ekonomi, atau politik dari suatu kelompok ataupun suatu daerah (Nazir, 2003).

Jenis data yang digunakan dalam penelitian ini adalah data primer dan sekunder. Pengumpulan data primer di peroleh melalui kuisioner dan wawancara pada nelayan tradisional. Sedangkan data sekunder diperoleh dari perpustakaan, jurnal serta informasi lain seperti hasil-hasil penelitian sebelumnya serta literatur yang berhubungan dengan penelitian.

\section{Populasi dan Sampel}

Populasi dalam penelitian ini adalah seluruh masyarakat yang berprofesi sebagai nelayan tradisional yang berada di Desa Lambada Lhok Kecamatan Baitussalam Kabupaten Aceh Besar. Penetapan sampel dalam penelitian ini dilakukan dengan menggunakan Simple Random Sampling (secara acak sederhana) karena populasi seluruhnya adalah homogen. Cara pengambilan sampel dari anggota populasi dengan menggunakan acak tanpa memperhatikan strata (tingkatan) dalam anggota populasi tersebut (Hadi, 2004).

Menurut Arikunto (2006), mengemukakan bahwa jika jumlah populasi kurang dari 100 orang maka sampelnya lebih baik diambil semua, tetapi apabila jumlah populasinya lebih besar dari 100 orang maka sampelnya dapat diambil antara $10-15 \%$ atau $20-25 \%$. Jadi, total nelayan tradisional yang menjadi sampel pada penelitian ini sebanyak 33 orang nelayan tradisional.

\section{Metode Analisis}

\section{Analisis Pendapatan}

Analisis pendapatan nelayan tradisional dengan rumus :

$$
\boldsymbol{\pi}=\mathbf{T R}-\mathbf{T C}
$$

(Soekartawi, 2002)

Dimana:

$\pi=$ Pendapatan $(\mathrm{Rp})$

$\mathrm{TR}=$ Total Revenue $(\mathrm{Rp})$

$\mathrm{TC}=$ Total Biaya Produksi $(\mathrm{Rp})$

Total Revenue (Total nilai produksi) dihitung dengan menggunakan rumus:

$$
\mathbf{T R}=\mathbf{P x Q}
$$

Dimana:

TR $=$ Total Penerimaan

$\mathrm{P}=$ Tingkat Harga

$\mathrm{Q}=$ Jumlah Unit Produksi

Biaya Total merupakan keseluruhan jumlah biaya produksi yang dikeluarkan. Biaya ini didapat dari menjumlahkan biaya tetap dan biaya tidak tetap. untuk melihat total biaya produksi (Total Cost) dapat dihitung dengan menggunakan rumus:

$$
\mathbf{T C}=\mathbf{F C}+\mathbf{V C}
$$

Dimana:

$\mathrm{TC}=$ Total Cost $($ total biaya produksi $)$

$\mathrm{FC}=$ Fixed Cost (biaya tetap)

$\mathrm{VC}=$ Variabel Cost (biaya tidak tetap)

Analisis Pendapatan dan Faktor-Faktor yang Mempengaruhi Pendapatan Nelayan Tradisional DI Desa Lambada Lhok Kecamatan Baitussalam Kabupaten Aceh Besar (Ivo Yolanda, Suyanti Kasimin, Mustafa Usman) 108 Jurnal Ilmiah Mahasiswa Pertanian Unsyiah, Vol.2, No 3, Agustus 2017: 106-117 


\section{Revenue Cost Ratio (R/C Ratio)}

Revenue Cost Ratio adalah nilai yang didapatkan dari perbandingan antara penerimaan dan biaya produksi. Dengan rumus sebagai berikut:

$\mathrm{R} / \mathrm{C}=$ Total penerimaan $\div$ Total Biaya produksi (Tim Penulis Penebar Swadaya, 2008)

Dengan kriteria keputusan sebagai berikut:

1. Jika R/C Ratio $>1$, maka usaha nelayan tradisional menguntungkan.

2. Jika $\mathrm{R} / \mathrm{C}$ Ratio $<1$, maka usaha nelayan tradisional tidak menguntungkan atau rugi.

3. Jika $\mathrm{R} / \mathrm{C}$ Ratio $=1$, maka usaha nelayan tradisional berada pada titik impas.

\section{Break Event Point (BEP)}

Break Event Point (BEP) adalah titik pulang pokok total revenue sama dengan total cost.

1. Berdasarkan Jumlah Produksi

BEP Produksi $=$ Total Biaya Produksi $\div$ Harga Jual (Alwi, 1994)

2. Berdasarkan Harga Produksi

BEP Harga Produksi = Total Biaya Produksi $\div$ Total Produksi $($ Alwi, 1994).

\section{Analisis Regresi Linear Berganda}

Rumus regresi linier berganda adalah sebagai berikut :

$$
\mathrm{Y}=\mathrm{a}+\mathrm{b}_{1} \mathrm{X}_{1}+\mathrm{b}_{2} \mathrm{X}_{2}+\mathrm{b}_{3} \mathrm{X}_{3}+\mathrm{b}_{4} \mathrm{X}_{4}+\mathrm{b}_{5} \mathrm{X}_{5}+\mathrm{e}
$$

Dimana :

$\mathrm{Y}=$ Pendapatan Nelayan Tradisional

$\mathrm{a}=$ Konstanta

$\mathrm{b}_{1}-\mathrm{b}_{5}=$ Koefisien regresi

$\mathrm{X}_{1}=$ Umur (Tahun)

$\mathrm{X}_{2}=$ Pendidikan (Tahun)

$\mathrm{X}_{3}=$ Pengalaman $($ Tahun $)$

$\mathrm{X}_{4}=$ Jumlah Tanggungan (Orang)

$\mathrm{X}_{5}=$ Biaya Operasional (Rupiah)

$\mathrm{e}=$ Kesalahan pengganggu

\section{Koefisien Determinasi $\left(\mathbf{R}^{2}\right)$}

$\mathrm{R}^{2}$ digunakan untuk mengukur seberapa jauh kemampuan model dalam menerangkan variasi variabel terikat. Sisanya dijelaskan oleh variabel lain yang tidak dimasukkan ke dalam model.

\section{Uji F}

Untuk mengetahui apakah masing-masing faktor tersebut secara serempak berpengaruh nyata atau tidak terhadap pendapatan nelayan tradisional (Y), maka digunakan uji F. Uji F dilakukan dengan cara membandingkan $\mathrm{F}_{\text {cari }}$ dengan $\mathrm{F}_{\text {tabel }}$.

$$
F_{\text {Cari }}=\frac{R^{2} / k}{\left(1-R^{2}\right) /(n-k-1)}
$$
(Sudjana, 2002)

Apabila perhitungan menunjukkan:

$\mathrm{F}_{\text {cari }}>\mathrm{F}_{\text {tabel }}=$ Pada taraf nyata 0,05 maka Ha diterima; $\mathrm{H}_{0}$ ditolak

$\mathrm{F}_{\text {cari }} \leq \mathrm{F}$ tabel $=$ Pada taraf nyata 0,05 maka Ha ditolak; $\mathrm{H}_{0}$ diterima

\section{Uji t}

Analisis Pendapatan dan Faktor-Faktor yang Mempengaruhi Pendapatan Nelayan Tradisional DI Desa Lambada Lhok Kecamatan Baitussalam Kabupaten Aceh Besar (Ivo Yolanda, Suyanti Kasimin, Mustafa Usman) 109 Jurnal Ilmiah Mahasiswa Pertanian Unsyiah, Vol.2, No 3, Agustus 2017: 106-117 
Untuk mengetahui apakah masing-masing faktor secara parsial berpengaruh nyata atau tidak terhadap pendapatan nelayan tradisional (Y), maka digunakan uji t.

$$
t_{\text {Cari }}=\frac{\left|a_{i}\right|}{S E_{a i}}
$$

Kriteria uji t:

Jika $\mathrm{t}_{\text {-hitung }} \leq \mathrm{t}$-tabel, maka $\mathrm{H}_{0}$ diterima; Ha ditolak

Jika t-hitung $>\mathrm{t}$-tabel, maka $\mathrm{H}_{0}$ ditolak; Ha diterima

Keterangan:

$\mathrm{H}_{0}=$ tidak ada pengaruh signifikan dari masing-masing faktor terhadap

pendapatan nelayan tradisional.

$\mathrm{Ha}=$ ada pengaruh signifikan dari masing-masing faktor terhadap pendapatan nelayan tradisional (Sudjana, 1989).

\section{HASIL DAN PEMBAHASAN}

\section{Karakteristik Responden}

Karakteristik responden merupakan gambaran umum tentang informasi responden yang bekerja sebagai nelayan tradisional di Desa Lambada Lhok. Adapun karakteristik responden dalam penelitian ini meliputi umur, tingkat pendidikan, pengalaman melaut dan jumlah tanggungan. Karakteristik responden dapat dilihat pada tabel berikut ini:

Tabel 1. Rata-Rata Karekteristik Nelayan Tradisional di Desa Lambada Lhok Kecamatan Baitussalam Kabupaten Aceh Besar Tahun 2016

\begin{tabular}{|l|l|l|c|}
\hline No & \multicolumn{1}{|c|}{ Karakteristik } & \multicolumn{1}{|c|}{ Satuan } & Rata- Rata \\
\hline 1 & Umur & Tahun & 49 \\
\hline 2 & Pendidikan & Tahun & 7 \\
\hline 3 & Pengalaman & Tahun & 38 \\
\hline 4 & Jumlah Tanggungan & Orang & 4 \\
\hline
\end{tabular}

Sumber: Data Primer (Diolah), 2016

Tabel 1 menunjukkan bahwa umur rata- rata nelayan tradisional di Desa Lambada Lhok adalah 49 tahun. Hal ini menunjukkan bahwa umur rata-rata nelayan tradisional masih tergolong dalam usia produktif untuk bekerja. Menurut Badan Pusat Statistik (BPS) kelompok umur produktif 15-65 tahun. Maka, dapat disimpulkan bahwa keseluruhan reponden tergolong pada umur produktif. Dalam Kamus Besar Bahasa Indonesia, usia produktif adalah usia ketika seseorang masih mampu bekerja dan menghasilkan sesuatu.

Rata-rata tingkat pendidikan nelayan tradisional di Desa Lambada Lhok adalah 7 tahun atau setara dengan Sekolah Menengah Pertama (SMP). Menurut Pratama (2012), tingkat pendidikan yang tinggi pada nelayan umumnya dapat meningkatkan informasi mengenai teknik penangkapan ikan dan keberanian dalam mengambil keputusan.

Rata-rata pengalaman nelayan di Desa Lambada Lhok adalah 38 tahun. Hal ini menunjukkan bahwa nelayan tradisional di daerah penelitian adalah berpengalaman. Menurut Sujarno (2008) Apabila seseorang dianggap nelayan yang telah berumur 15-30 tahun, >30 tahun dianggap sebagai nelayan yang berpengalaman. Hal ini merupakan kategori atau klasifikasi untuk menentukan banyak jumlah tangkapan ikan dilaut.

Analisis Pendapatan dan Faktor-Faktor yang Mempengaruhi Pendapatan Nelayan Tradisional DI Desa Lambada Lhok Kecamatan Baitussalam Kabupaten Aceh Besar (Ivo Yolanda, Suyanti Kasimin, Mustafa Usman) 
Rata-rata jumlah tanggungan nelayan di Desa Lambada Lhok sebanyak 4 orang. Menurut Hasyim (2006), jumlah tanggungan keluarga adalah salah satu faktor yang perlu diperhatikan dalam menentukan pendapatan dalam memenuhi kebutuhannya. Banyaknya jumlah tanggungan keluarga akan mendorong nelayan untuk melakukan banyak aktivitas terutama dalam mencari dan menambah pendapatan keluarganya.

\section{Analisis Pendapatan}

Pendapatan yang diperoleh dari nelayan tradisional di Desa Lambada Lhok dihitung dari total penerimaan dikurangi total biaya operasional. Berikut ini hasil perhitungan pendapatan nelayan tradisional:

\subsection{Biaya Produksi}

Biaya produksi pada penelitian ini adalah biaya yang dikeluarkan oleh pemilik kapal dan nelayan tradisional selama melaut. Nelayan tradisional melakukan kegiatan melaut selama 24 hari dalam 1 bulan. Biaya produksi terdiri dari biaya tetap dan biaya tidak tetap. Berikut ini hasil perhitungan biaya tetap dan biaya tidak tetap dari nelayan tradisional:

a. Biaya Tetap

Pada penelitian ini, biaya tetap dikeluarkan oleh pemilik kapal. Nelayan tradisional hanya mengeluarkan biaya operasional saja. Adapun rata - rata biaya tetap yang dikeluarkan pemilik kapal dapat dilihat di tabel 2 berikut ini:

Tabel 2. Rata-Rata Biaya Tetap Pemilik Kapal per Bulan Tahun 2016 (Asumsi 1 bulan = 24 hari)

\begin{tabular}{|c|l|c|r|c|r|}
\hline No & Perlengkapan & Satuan & $\begin{array}{c}\text { Biaya } \\
\text { Perlengkapan } \\
\text { (Rp) }\end{array}$ & $\begin{array}{c}\text { Umur } \\
\text { Ekonomis } \\
\text { (Bulan) }\end{array}$ & $\begin{array}{c}\text { Biaya Penyusutan } \\
\text { (Rp/Bln) }\end{array}$ \\
\hline 1 & Mesin & Unit & 8.580 .303 & 60 & 159.167 \\
\hline 2 & Fiber & Unit & 773.333 & 60 & 12.889 \\
\hline 3 & Umpan Ikan & Buah & 55.152 & 1 & 55.152 \\
\hline 4 & Padok & Gulungan & 20.545 & 2 & 10.273 \\
\hline 5 & Senter & Buah & 107.758 & 12 & 800.000 \\
\hline 6 & Timah & Buah & 400.000 & 1 & 15.000 \\
\hline 7 & Pelampung & Buah & 15.000 & 1 & 500.000 \\
\hline 8 & Kail & Kotak & 500.000 & 1 & $\mathbf{1 . 1 6 1 . 4 6 1}$ \\
\hline \multicolumn{2}{|c|}{ Total }
\end{tabular}

Sumber: Data Primer (Diolah), 2016

Tabel 2 menunjukkan bahwa besarnya rata-rata biaya perlengkapan yang dikeluarkan oleh pemilik kapal sebesar Rp.10.452.091/Bulan. Biaya perlengkapan paling besar yang dikeluarkan oleh nelayan tradisional yaitu pada mesin sebesar Rp. 8.580.303/Bulan dan biaya terendah yaitu pelampung dengan harga Rp.15.000/Bulan. Untuk rata-rata biaya penyusutan alat sebesar Rp.1.161.461/Bulan.

b. Biaya Operasional Nelayan Tradisional

Biaya operasional merupakan seluruh biaya yang dikeluarkan oleh nelayan tradisional setiap melaut. Total biaya operasional dapat dilihat pada tabel berikut ini:

Tabel 3. Total Biaya Operasional Nelayan Tradisional di Desa Lambada Lhok Tahun 2016 (1 bulan $=24$ Hari)

Analisis Pendapatan dan Faktor-Faktor yang Mempengaruhi Pendapatan Nelayan Tradisional DI Desa Lambada Lhok Kecamatan Baitussalam Kabupaten Aceh Besar (Ivo Yolanda, Suyanti Kasimin, Mustafa Usman) 


\begin{tabular}{|c|l|c|r|}
\hline No & Jenis Pengeluaran & Satuan & Biaya Operasional (Rp/BIn) \\
\hline 1 & Kopi & Gelas & 346.909 \\
\hline 2 & Kue & Potong & 154.909 \\
\hline 3 & Solar & Liter & 1.344 .618 \\
\hline 4 & Es & Bungkus & 240.000 \\
\hline 5 & Rokok & Bungkus & 365.455 \\
\hline \multicolumn{2}{|c|}{ Jumlah } & $\mathbf{2 . 4 5 1 . 8 9 1}$ \\
\hline
\end{tabular}

Sumber:Data Primer (Diolah), 2016

Total biaya operasional nelayan tradisional sebesar Rp.2.451.891/Bulan. Pada daerah penelitian, nelayan tradisional hanya mengeluarkan biaya operasional. Untuk biaya tetap nelayan tradisional dikeluarkan oleh pemilik kapal.

\subsection{Total Penerimaan}

Total penerimaan adalah jumlah seluruh pemasukan yang diterima oleh nelayan tradisional sebelum dikurangi dengan total biaya operasional. Total Penerimaan pada nelayan tradisional per bulan dapat dilihat pada tabel berikut ini:

Tabel 4. Jumlah Penerimaan Nelayan Tradisional perbulan di Desa Lambada Lhok Tahun 2016

\begin{tabular}{|c|l|c|c|c|c|c|}
\hline No & $\begin{array}{c}\text { Jenis } \\
\text { Ikan }\end{array}$ & $\begin{array}{c}\text { Penerimaan } \\
\text { Pemilik } \\
\text { Kapal } \\
(\text { Rp/Bln })\end{array}$ & $\begin{array}{c}\text { Total } \\
\text { Biaya } \\
\text { Tetap } \\
(\text { Rp/BIn) }\end{array}$ & $\begin{array}{c}\text { Penerimaan } \\
\text { Bersih } \\
\text { Pemilik } \\
\text { Kapal } \\
\text { (Rp/Bln })\end{array}$ & $\begin{array}{c}\text { Penerimaan } \\
\text { Nelayan } \\
\text { Tradisional } \\
(\text { Rp/Bln })\end{array}$ & $\begin{array}{c}\text { Upah } \\
(\text { Rp/Bln })\end{array}$ \\
\hline 1 & Tongkol & 7.821 .818 & & & & \\
\hline 2 & Kerapu & 6.245 .455 & & & & \\
\hline 3 & Rambeu & 4.000 .000 & 1.161 .461 & 25.103 .793 & 2.510 .379 & 1.200 .000 \\
\hline 4 & Kakap & 4.072 .727 & & & & \\
\hline 5 & Tenggiri & 4.109 .091 & & & & \\
\hline \multicolumn{2}{|l}{ Jumlah } & $\mathbf{2 6 . 2 4 9 . 0 9 1}$ & $\mathbf{1 . 1 6 1 . 4 6 1}$ & $\mathbf{2 5 . 1 0 3 . 7 9 3}$ & $\mathbf{2 . 5 1 0 . 3 7 9}$ & $\mathbf{1 . 2 0 0 . 0 0 0}$ \\
\hline
\end{tabular}

Sumber: Data Primer (Diolah), 2016

Tabel 4 menunjukkan bahwa total penerimaan nelayan tradisional di Desa Lambada Lhok sebesar Rp. 3.710.379/bulan. Pada daerah penelitian, nelayan tradisional menerima 10\% dari hasil melaut. Nelayan tradisional juga menerima upah dari pemilik kapal sebanyak Rp. 50.000/ hari. Upah ini diterima nelayan walaupun nelayan tidak mendapatkan ikan dalam setiap trip.

\subsection{Pendapatan}

Pendapatan nelayan adalah selisih antara total penerimaan (total revenue) dan total biaya operasional nelayan tradisional dalam sebulan. Untuk mengetahui pendapatan nelayan tradisional di Desa Lambada lhok dapat dilihat pada analisis berikut ini:

Pendapatan:

$\mathbf{I}=$ TR- TC

Maka diperoleh:

$\Pi=($ Total Penerimaan $)-($ Total Biaya Operasional $)$

Analisis Pendapatan dan Faktor-Faktor yang Mempengaruhi Pendapatan Nelayan Tradisional DI Desa Lambada Lhok Kecamatan Baitussalam Kabupaten Aceh Besar (Ivo Yolanda, Suyanti Kasimin, Mustafa Usman) 112 Jurnal Ilmiah Mahasiswa Pertanian Unsyiah, Vol.2, No 3, Agustus 2017: 106-117 


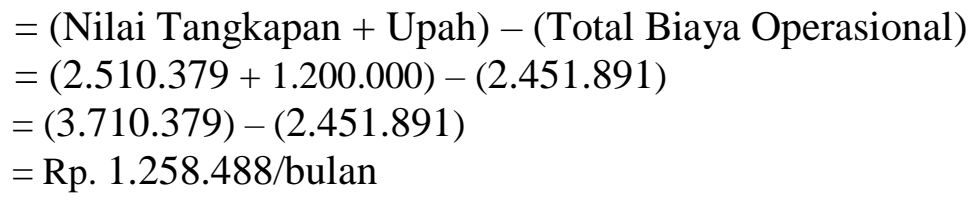

Hasil perhitungan diatas menunjukkan bahwa pendapatan yang diterima nelayan tradisional di Desa Lambada Lhok sebesar Rp. 1.258.488/bulan. Ini didapat dari hasil selisih total nilai tangkapan dan biaya upah dikurangi dengan biaya operasional.

\subsection{R/C (Revenue Cost Ratio)}

Revenue Cost Ratio (R/C) pada nelayan tradisional di Desa Lambada Lhok adalah sebagai berikut :

Tabel 5. R/C (Revenue Cost Ratio) pada Nelayan Tradisional di Desa Lambada Lhok Tahun 2016

\begin{tabular}{|l|r|r|}
\hline Uraian & Total Penerimaan (Rp/bln) & Total Biaya Operasional (Rp/Bln) \\
\hline Jumlah & 122.442 .517 & 80.912 .400 \\
\hline Rata - rata & 3.710 .379 & \\
\hline R/C & \multicolumn{2}{|c|}{$\mathbf{1 , 5 1}$} \\
\hline
\end{tabular}

Sumber:Data Primer (Diolah), 2016

Tabel 5 menjelaskan bahwa $\mathrm{R} / \mathrm{C}$ ratio pada nelayan tradisional di Desa Lambada Lhok sebesar 1,51. Berdasarkan dengan kriteria pengambilan keputusan apabila $\mathrm{R} / \mathrm{C}$ ratio $>1$, maka pendapatan nelayan tradisional di daerah penelitian menguntungkan.

\subsection{BEP (Break Event Point)}

Break Event Point (BEP) pada nelayan tradisional adalah sebagai berikut :

Tabel 6. BEP (Break Event Point) pada Nelayan Tradisional di Desa Lambada Lhok Tahun 2016

\begin{tabular}{|l|l|r|r|c|c|r|}
\hline No & Jenis Ikan & $\begin{array}{c}\text { Total Biaya } \\
\text { Operasional } \\
(\mathbf{R p} / \mathbf{B l n})\end{array}$ & $\begin{array}{c}\text { Harga } \\
\text { Jual } \\
(\mathbf{R p / K g})\end{array}$ & $\begin{array}{c}\text { Total } \\
\text { Produksi } \\
(\mathbf{K g} / \mathbf{B l n})\end{array}$ & $\begin{array}{c}\text { BEP } \\
\text { Produksi } \\
(\mathbf{K g} / \mathbf{B l n})\end{array}$ & $\begin{array}{c}\text { BEP Harga } \\
(\mathbf{R p} / \mathbf{K g})\end{array}$ \\
\hline 1 & Tongkol & 1.470 .006 & 15.000 & 521 & 98 & 2.821 \\
\hline 2 & Kerapu & 296.258 & 60.000 & 105 & 5 & 2.821 \\
\hline 3 & Rambeu & 225.721 & 50.000 & 80 & 5 & 2.821 \\
\hline 4 & Kakap & 228.542 & 50.000 & 81 & 5 & 2.821 \\
\hline 5 & Tenggiri & 231.364 & 45.000 & 82 & 5 & $\mathbf{1 4 . 1 0 5}$ \\
\hline \multicolumn{2}{|c|}{ Total } & $\mathbf{2 . 4 5 1 . 8 9 1}$ & $\mathbf{2 2 0 . 0 0 0}$ & $\mathbf{8 6 9}$ & $\mathbf{1 1 8}$ & \\
\hline
\end{tabular}

Sumber: Data Primer (Diolah), 2016

Tabel 6 menjelaskan bahwa BEP (Break Event Point) atau titik pulang pokok pada produksi ikan tongkol sebesar $98 \mathrm{Kg}$ yang artinya titik pulang pokok ikan tongkol terjadi pada saat produksi $98 \mathrm{Kg}$. BEP pada ikan kerapu sebesar $5 \mathrm{Kg}$ yang artinya titik pulang pokok pada ikan kerapu terjadi pada saat produksi $5 \mathrm{Kg}$. BEP untuk ikan Rambeu sebesar $5 \mathrm{Kg}$ yang artinya titik pulang pokok pada ikan Rambeu terjadi pada saat produksi $5 \mathrm{Kg}$. BEP untuk ikan kakap sebesar $5 \mathrm{Kg}$ yang artinya titik pulang pokok pada ikan kakap terjadi pada saat

Analisis Pendapatan dan Faktor-Faktor yang Mempengaruhi Pendapatan Nelayan Tradisional DI Desa Lambada Lhok Kecamatan Baitussalam Kabupaten Aceh Besar (Ivo Yolanda, Suyanti Kasimin, Mustafa Usman) 113 Jurnal Ilmiah Mahasiswa Pertanian Unsyiah, Vol.2, No 3, Agustus 2017: 106-117 
produksi $5 \mathrm{Kg}$. BEP untuk ikan tenggiri sebesar $5 \mathrm{~kg}$ yang artinya titik pulang pokok pada ikan tenggiri terjadi pada saat produksi $5 \mathrm{Kg}$.

Pada tabel 6 juga dapat dilihat bahwa BEP harga atau balik modal untuk setiap jenis ikan sama. BEP harga ikan tongkol sebesar Rp. $2.821 / \mathrm{Kg}$ yang artinya titik pulang pokok ikan tongkol dicapai pada harga minimal Rp. $2.821 / \mathrm{Kg}$. BEP harga ikan kerapu sebesar Rp. $2.821 / \mathrm{Kg}$ yang artinya titik pulang pokok untuk ikan kerapu dicapai pada harga minimal Rp. 2.821/Kg. BEP harga ikan rambeu sebesar Rp. 2.821/Kg yang artinya titik pulang pokok pada ikan rambeu dicapai pada harga minimal Rp. 2.821/Kg. BEP harga ikan kakap sebesar Rp. $2.821 / \mathrm{Kg}$ yang artinya titik pulang pokok ikan kakap dicapai pada harga minimal Rp. $2.821 / \mathrm{Kg}$. BEP harga ikan tenggiri sebesar Rp. $2.821 / \mathrm{Kg}$ yang artinya titik pulang pokok ikan tenggiri dicapai pada harga minimal Rp. $2.821 / \mathrm{Kg}$.

\section{Faktor-Faktor yang Mempengaruhi Pendapatan Nelayan Tradisional}

Berdasarkan hipotesis kedua bahwa faktor-faktor yang mempengaruhi pendapatan nelayan tradisional yaitu umur, pendidikan, pengalaman, jumlah tanggungan dan biaya operasional. Berikut ini hasil analisis faktor-faktor yang mempengaruhi pendapatan nelayan tradisonal:

Tabel 7. Hasil Analisis Faktor-Faktor yang Mempengaruhi Pendapatan Nelayan Tradisional di Desa Lambada Lhok Tahun 2016

\begin{tabular}{|c|c|c|c|c|}
\hline Variabel & Koefisien & $\mathbf{t}_{\text {hitung }}$ & $\mathbf{F}_{\text {hitung }}$ & $\mathbf{R}^{2}$ \\
\hline $\mathrm{X}_{1}$ (Umur) & 9353,613 & 2,655 & \multirow[t]{5}{*}{74,418} & \multirow[t]{5}{*}{0,932} \\
\hline $\mathrm{X}_{2}($ Pendidikan $)$ & 20368,741 & 2,366 & & \\
\hline $\mathrm{X}_{3}$ (Pengalaman) & 3791,193 & 2,062 & & \\
\hline $\mathrm{X}_{4}$ (Jumlah Tanggungan) & 13837,947 & 2,188 & & \\
\hline $\mathrm{X}_{5}$ (Biaya Operasional) & $-0,360$ & $-3,740$ & & \\
\hline Constanta & 1335026,412 & & & \\
\hline
\end{tabular}

Sumber: Data Primer (Diolah), 2016.

Adapun persamaan regresi linear berganda yaitu:

$Y=1335026+9353 X_{1}+20368 X_{2}+3,791 X_{3}+413837 X_{4}-0,360 X_{5}$

Berdasarkan hasil analisis diatas dapat diketahui bahwa:

a. Koefisien Determinasi $\left(\mathrm{R}^{2}\right)$

Koefisien determinasi $\left(\mathrm{R}^{2}\right)$ digunakan untuk mengukur seberapa jauh kemampuan variabel bebas dalam menjelaskan variabel terikat. Berdasarkan tabel 13 diatas hasil regresi koefisien diterminasi diatas sebesar 0,932 yang artinya bahwa sebesar 93,20\% variabel pendapatan dapat dipengaruhi oleh faktor umur $\left(\mathrm{X}_{1}\right)$, pendidikan $(\mathrm{X} 2)$, pengalaman $\left(\mathrm{X}_{3}\right)$, jumlah tanggungan $\left(\mathrm{X}_{4}\right)$ dan biaya operasional $\left(\mathrm{X}_{5}\right)$ sedangkan $6,8 \%$ dapat dijelaskan oleh faktor-faktor lain diluar variabel penelitian.

b. Uji F

Uji ini dilakukan untuk mengetahui apakah variabel bebas yang terdiri dari umur, pengalaman, pendidikan, jumlah tanggungan dan biaya operasional secara bersama-bersama berpengaruh nyata terhadap pendapatan nelayan tradisional di Desa Lambada Lhok.

Analisis Pendapatan dan Faktor-Faktor yang Mempengaruhi Pendapatan Nelayan Tradisional DI Desa Lambada Lhok Kecamatan Baitussalam Kabupaten Aceh Besar (Ivo Yolanda, Suyanti Kasimin, Mustafa Usman) 114 Jurnal Ilmiah Mahasiswa Pertanian Unsyiah, Vol.2, No 3, Agustus 2017: 106-117 
Berdasarkan tabel 13 diatas diketahui bahwa nilai $F_{\text {hitung }}$ sebesar 74,148 dan nilai $F_{\text {tabel }}$ dengan derajat pembilang sebesar 5 dan derajat penyebut sebesar 27 dan $\alpha$ sebesar 0,05 adalah 2,57. Nilai tersebut menunjukkan bahwa $F_{h i t u n g}>F_{\text {tabel }}$ sehingga terima $\mathrm{H}_{a}$ dan tolak $\mathrm{H}_{0}$. Artinya yaitu variabel bebas secara serempak berpengaruh nyata terhadap pendapatan nelayan tradisional di Desa Lambada Lhok.

\section{c. Uji t}

Uji ini dilakukan untuk mengetahui apakah variabel bebas yang terdiri dari umur, pengalaman, pendidikan, jumlah tanggungan dan biaya operasional secara parsial berpengaruh nyata terhadap pendapatan nelayan tradisional di Desa Lambada Lhok. Untuk hasil nilai tabel yaitu sebesar 2,051 dengan nilai df sebesar 27 dan pada $\alpha$ sebesar 0,05 .

\section{a. Umur}

Setiap bertambahnya umur nelayan tradisional 1 tahun maka pendapatan nelayan tradisional akan bertambah sebesar Rp.9.353 per bulan dengan asumsi variabel $\left(\mathrm{X}_{2}, \mathrm{X}_{3}, \mathrm{X}_{4}\right.$,

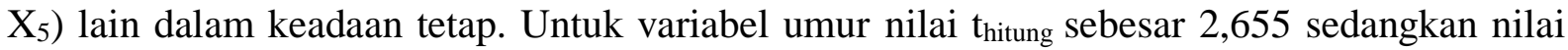
$t_{\text {tabel }}$ sebesar 2,051. Hal ini menunjukkan bahwa $t_{\text {hitung }}>t_{\text {tabel }}$ sehingga terima $\mathrm{H}_{\mathrm{a}}$ dan tolak $\mathrm{H}_{\mathrm{o}}$. Artinya variabel umur berpengaruh nyata terhadap pendapatan nelayan tradisional di Desa Lambada Lhok. Umur nelayan dapat mempengaruhi tingkat pendapatan nelayan, hal tersebut didukung dengan kurangnya pengalaman melaut nelayan muda sehingga berkurangnya hasil tangkapan dan juga jumlah pendapatannya rendah. Dengan pengalaman yang memadai seorang nelayan akan dengan mudah mendapatkan hasil tangkapannya karena seorang nelayan yang berpengalaman dapat mengetahui dimana tempat ikan berkumpul dan menangkapnya dengan kemampuanya.

b. Pendidikan

Pada variabel pendidikan, setiap bertambahnya 1 tingkat jenjang pendidikan maka akan bertambahnya pendapatan nelayan tradisional sebesar Rp. 20.368 per bulan dengan asumsi variabel $\left(\mathrm{X}_{1}, \mathrm{X}_{3}, \mathrm{X}_{4}, \mathrm{X}_{5}\right)$ lain dalam keadaan tetap. Untuk nilai thitung sebesar 2,366 sedangkan nilai $t_{\text {tabel }}$ sebesar 2,051. Hal ini menunjukkan bahwa $t_{\text {hitung }}>t_{\text {tabel }}$ sehingga terima $\mathrm{H}_{\mathrm{a}}$ dan tolak $\mathrm{H}_{\mathrm{o}}$. Artinya variabel pendidikan berpengaruh nyata terhadap pendapatan nelayan tradisional di Desa Lambada Lhok. Hal ini dikarenakan semakin tinggi tingkat pendidikan nelayan maka akan semakin baik pula pola pikir dalam mengembangkan inovasi untuk meningkatkan hasil produksi ikan sehingga pendapatanpun akan lebih besar.

c. Pengalaman

Setiap bertambahnya pengalaman seorang nelayan tradisional sebanyak 1 tahun, maka akan meningkatkan pendapatan sebesar Rp.3.791 per bulan dengan asumsi variabel $\left(\mathrm{X}_{1}, \mathrm{X}_{2}\right.$, $\mathrm{X}_{4}, \mathrm{X}_{5}$ ) lain dalam keadaan tetap. Nilai thitung pada variabel pengalaman sebesar 2,062 sedangkan nilai $t_{\text {tabel }}$ sebesar 2,051. Hal ini menunjukkan bahwa $t_{\text {hitung }}>t_{\text {tabel }}$ sehingga terima $\mathrm{H}_{\mathrm{a}}$ dan Tolak $\mathrm{H}_{0}$. Artinya untuk variabel pengalaman berpengaruh nyata terhadap pendapatan nelayan tradisional. Hal ini dikarenakan jika nelayan semakin berpengalaman maka nelayan akan lebih mampu menguasai alat tangkap dan daerah operasi yang akan menyebabkan semakin tingginya produktivitas hasil tangkapan ikan di laut.

d. Jumlah Tanggungan

Setiap kenaikan jumlah tanggungan sebanyak 1 orang, maka akan meningkatkan pendapatan sebesar Rp. 13.837 per bulan dengan asumsi variabel $\left(\mathrm{X}_{1}, \mathrm{X}_{2}, \mathrm{X}_{3}, \mathrm{X}_{5}\right)$ lain dalam keadaan tetap. Pada variabel jumlah tanggungan nilai $t_{\text {hitung }}$ sebesar 2,118 sedangkan nilai $t_{\text {tabel }}$

Analisis Pendapatan dan Faktor-Faktor yang Mempengaruhi Pendapatan Nelayan Tradisional DI Desa Lambada Lhok Kecamatan Baitussalam Kabupaten Aceh Besar (Ivo Yolanda, Suyanti Kasimin, Mustafa Usman) 115 Jurnal Ilmiah Mahasiswa Pertanian Unsyiah, Vol.2, No 3, Agustus 2017: 106-117 
sebesar 2,051. Hal ini menunjukkan bahwa $t_{\text {hitung }}>t_{\text {tabel }}$ sehingga terima $\mathrm{H}_{\mathrm{a}}$ dan Tolak $\mathrm{H}_{0}$. Artinya untuk variabel jumlah tanggungan berpengaruh nyata terhadap pendapatan nelayan tradisional. Hal ini dikarenakan jika banyaknya jumlah tanggungan keluarga akan mendorong nelayan untuk melakukan banyak aktivitas terutama dalam mencari dan menambah pendapatan keluarga.

e. Biaya Operasional

Setiap kenaikan biaya operasional sebesar Rp.1 per bulan, maka akan menurunkan pendapatan sebesar Rp. 360 per bulan dengan asumsi variabel $\left(\mathrm{X}_{1}, \mathrm{X}_{2}, \mathrm{X}_{3}, \mathrm{X}_{4}\right)$ lain dalam keadaan tetap. Nilai thitung pada variabel biaya operasional sebesar 3,740 sedangkan nilai $t_{\text {tabel }}$ sebesar 2,051. Hal ini menunjukkan bahwa thitung $>t_{\text {tabel }}$ sehingga terima $\mathrm{H}_{\mathrm{a}}$ dan Tolak $\mathrm{H}_{0}$. Artinya untuk variabel biaya operasional berpengaruh nyata terhadap pendapatan nelayan tradisional. Hal ini dikarenakan di daerah penelitian, nelayan hanya mengeluarkan biaya operasional saja dan digunakan untuk pengeluaran dirinya sendiri dalam melaut.

\section{SIMPULAN DAN SARAN}

\section{Simpulan}

Berdasarkan penelitian yang telah dilakukan, maka dapat diambil kesimpulan sebagai berikut:

1. Usaha nelayan tradisional di Desa Lambada Lhok Kecamatan Baitussalam dapat memberikan pendapatan yang layak bagi nelayan tradisional dilihat dari hasil perhitungan pendapatan sebesar Rp. 1.258.488/bulan dengan nilai R/C yang didapat yang didapat sebesar 1,51 .

2. Hasil Uji F menunjukkan bahwa variabel umur, pendidikan, pengalaman jumlah tanggungan dan biaya operasional secara bersama-sama berpengaruh nyata terhadap pendapatan nelayan tradisional di Desa Lambada Lhok. Hasil Uji t menunjukkan bahwa variabel umur, pendidikan, pengalaman, jumlah tanggungan dan biaya operasional secara parsial berpengaruh nyata terhadap pendapatan nelayan tradisional. Untuk ke-5 variabel tersebut dapat menjelaskan bahwa pengaruh pendapatan sebesar 93,2\% dan sisanya dijelaskan oleh variabel lain diluar model.

\section{Saran}

Berdasarkan hasil penelitian dan kesimpulan diatas, maka penulis memberikan beberapa saran. Adapun saran-saran sebagai berikut:

1. Untuk mendorong peningkatan pendapatan dan kesejahteraan kehidupan masyarakat pesisir khususnya nelayan sudah seharusnya pemerintah dan Dinas Perikanan bekerja sama mencari solusi dari ketimpangan pendapatan pada musim barat dan timur yang jauh berbeda, salah satu solusinya adalah memberikan pelatihan dalam memanajemen keuangan, contohnya memberikan tabungan khusus nelayan. Juga pemerintah dan Dinas perikanan harus segera mencari solusi dari kosongnya kegiatan para nelayan di musim barat, contohnya memberikan penyuluhan-penyuluhan.

2. Untuk mendorong kemampuan dari nelayan maka pemerintah terutama Dinas Perikanan dapat memberikan pembinaan dan pengembangan kemampuan nelayan dalam kemampuan menangkap ikan dan juga meningkatkan teknologi dalam menangkap ikan dengan

Analisis Pendapatan dan Faktor-Faktor yang Mempengaruhi Pendapatan Nelayan Tradisional DI Desa Lambada Lhok Kecamatan Baitussalam Kabupaten Aceh Besar (Ivo Yolanda, Suyanti Kasimin, Mustafa Usman) 116 Jurnal Ilmiah Mahasiswa Pertanian Unsyiah, Vol.2, No 3, Agustus 2017: 106-117 
teknologi yang tepat guna karena di daerah penelitian nelayan masih menggunakan alat tangkap yang tradisional.

\section{DAFTAR PUSTAKA}

Alwi, S. 1994. Alat-alat Analisis Dalam Pembelajaran. Andi Offset. Yogyakarta.

Arikunto, S. 2006. Prosedur penelitian. PT Rineka Cipta. Jakarta.

Dumairy. 2004. Matematika Untuk Bisnis dan Ekonomi. Bina aksara. Jakarta.

Hasyim, H. 2006. Analisis Hubungan Karakteristik Petani Kopi Terhadap Pendapatan. Jurnal Komunikasi Penelitian. USU. Medan.

Hadi, S. 2004. Metodologi Research Jilid III. Penerbit Andi. Yogyakarta.

Kusnadi. 2003. Akar Kemiskinan Nelayan. Yogyakarta.

Mulyadi, S. 2005. Ekonomi Kelautan. Rajagrafindo Persada. Jakarta.

Nazir, M. 2003. Metode Penelitian. Ghalia Indonesia. Jakarta.

Pratama, Dkk. 2012. Analisis Pendapatan Nelayan Tradisional Pancing Ulur di Kecamatan Manggar, Kabupaten Belitung Timur. Jurnal Perikanan dan Kelautan, Volume 3, No. 3.

Retnowati, E. 2011. Nelayan Indonesia Dalam Pusaran Kemiskinan Struktural Perspektif Sosial, Ekonomi dan Hukum. Jurnal Perspektif, Volume 16 No 3, 149-159.

Soekartawi. 2002. Analisis Usaha Tani. UI - Press. Jakarta.

Sudjana. 1989. Metode Statistika. PT. Tarsito. Bandung.

Sudjana. 2002. Metode Statistika. PT. Tarsito. Bandung.

Sujarno. 2008. Analisis Faktor-Faktor yang Mempengaruhi Pendapatan Nelayan Di Kabupaten Langkat. Sekolah Pasca Sarjana. Tesis. Universitas Sumatera Utara. Medan.

Tim Penulis Penebar Swadaya. 2008. Agribisnis Perikanan. Penebar Swadaya. Jakarta. 